\title{
An 8 week open-label interventional multicenter study to evaluate the lung clearance index as endpoint for clinical trials in cystic fibrosis patients $\geq 6$ years of age, chronically infected with Pseudomonas aeruginosa
}

Sivagurunathan Sutharsan ( $\square$ sivagurunathan.sutharsan@rlk.uk-essen.de ) https://orcid.org/0000-0003-4069-4900

\section{Susanne Naehrig}

Ludwig-Maximilians-Universitat Munchen

Uwe Mellies

Universitat Duisburg-Essen

Christian Sieder

Novartis Pharma GmbH

joerg Zeigler

Novartis Pharma GmbH

\section{Research article}

Keywords: cystic fibrosis, forced expiratory volume in 1 second, lung clearance index, tobramycin, Pseudomonas aeruginosa, antibiotics, clinical trials

Posted Date: March 3rd, 2020

DOl: https://doi.org/10.21203/rs.3.rs-15870/v1

License: (c) (i) This work is licensed under a Creative Commons Attribution 4.0 International License. Read Full License

Version of Record: A version of this preprint was published at BMC Pulmonary Medicine on June 12th, 2020. See the published version at https://doi.org/10.1186/s12890-020-01201-y. 


\section{Abstract}

Background Forced expiratory volume in 1 second (FEV 1 ) is the only parameter currently recognized as a surrogate endpoint in cystic fibrosis (CF) trials. However, FEV 1 is relatively insensitive to changes in the small airways of patients with milder lung disease. This pilot study aimed to evaluate the lung clearance index ( $\mathrm{LCl})$ as a marker for use in efficacy trials with inhaled antibiotics in CF.

Methods This open-label, single-arm study enrolled CF patients with Pseudomonas aeruginosa infection, who were treated with tobramycin (28-day on/off regime). FEV $1, \mathrm{LCl}$ and bacterial load in sputum (CFU) were assessed at baseline, after 1, 4 and 8 weeks of treatment.

Results All patients $(\mathrm{n}=17)$ showed elevated $\mathrm{LCl}$ of $>11$ despite 3 patients having normal FEV $1(>90 \%$ predicted) at baseline. Overall, LCl improved in 8 (47\%) patients and FEV 1 in 9 (53\%) patients. At week 4, $\mathrm{LCl}$ decreased by 0.88 , FEV 1 increased by $0.52 \%$, and P. aeruginosa reduced by $30481.3 \mathrm{CFU} / \mathrm{mL}$. These changes were however statistically non-significant. Six adverse events occurred in 5/17 (29.4\%) patients, most of which were mild-to-moderate in severity.

Conclusions Due to the low evaluable sample size, no specific trend was observed related to the changes between LCI, FEV 1 and CFU. Based on the individual data from this study and from recently published literature, $\mathrm{LCl}$ has been shown to be a more sensitive parameter than FEV 1 for lung function. However, $\mathrm{LCl}$ alone does not seem to be the ideal clinical endpoint for efficacy studies with antibiotic treatment in small groups of CF patients.

Trial registration : The study is registered with ClinicalTrials.gov, identifier: NCT02248922

\section{Background}

Cystic fibrosis (CF) is a life-limiting, autosomal recessive genetic disease [1], characterized by a reduced quantity and/or function of the cystic fibrosis transmembrane conductance regulator (CFTR) protein, leading to an impaired mucociliary clearance of the airways, followed by chronic inflammation, infection and thus progressive and irreversible loss of lung function [2]. The main driver of lung function decline beyond infancy in people with CF is the chronic infection with Pseudomonas aeruginosa [3]. Although it is a complex multiorgan and multifactorial disease, the chronic lung infection by P. aeruginosa is the primary cause of morbidity. Therefore, an antibiotic maintenance therapy is the preferred standard treatment in these patients. [2]. Inhaled tobramycin typically given in 28 day cycles of one month on and one month off periods, is recommended for treating individuals with CF aged $\geq 6$ years, who have mild to moderate lung disease with persistent $P$. aeruginosa infection [4].

Currently, forced expiratory volume in one second $\left(\mathrm{FEV}_{1}\right)$ and rate of $\mathrm{FEV}_{1}$ decline are the only accepted surrogate markers for assessing lung function decline [5]. However, with significant advances in the care of patients with CF, such as the newly introduced CFTR-targeted therapies and considerable improvement in survival rates, the rate of decline in $\mathrm{FEV}_{1}$ has slowed $[6,7]$, leading to a preservation of spirometric lung 
function within the normal range into young adulthood $[8,9]$. Moreover, $\mathrm{FEV}_{1}$ is insensitive during early stages of lung disease resulting in normal spirometry findings, despite the progression of structural damage in lungs, for example in bronchiectasis. Therefore, the reliability on $\mathrm{FEV}_{1}$ as an indicator of disease progression especially in the early stages of lung disease has become questionable $[9,10]$. Increasing evidence suggest that in patients with $\mathrm{CF}$, pulmonary deterioration starts early in life and can occur in the absence of respiratory symptoms at normal lung function in terms of FEV ${ }_{1}$ [11]. Thus, there is a need for early intervention before onset of irreversible lung damage based on alternative clinically sensitive surrogate markers for detection of early CF lung disease [12].

A multiple breath washout (MBW) test assessing ventilation inhomogeneity has been shown to be a sensitive lung function test to detect early pathology in patients with CF [12]. The most commonly reported MBW outcome is the lung clearance index $(\mathrm{LCl})$, which is a robust, noninvasive technique to detect early lung disease changes across all age groups $[13,14]$. Consequently, $\mathrm{LCl}$ has been evaluated as a new sensitive surrogate endpoint for measuring trial outcomes focusing on the early stages of disease [13]. LCl was used for the first time as the primary study endpoint in a pivotal trial in children (6-11 years) with CF treated with an oral combination of CFTR modulators, lumacaftor (LUM) and ivacaftor (IVA). Treatment with LUM/IVA, demonstrated a statistically significant improvement in lung function, as measured by $\mathrm{LCl}_{2.5}$ and percent predicted $\mathrm{FEV}_{\mathrm{I}}\left(\mathrm{ppFEV}_{1}\right)$, versus placebo in children with $\mathrm{CF}$ homozygous for F508del-CFTR [15]. However, there is still very limited data available on the use of $\mathrm{LCl}$ as a clinical endpoint for CF patients treated with inhaled antibiotics.

The aim of the present study was to examine the clinical utility of LCl for assessing short-term clinical response to inhaled tobramycin antibiotic therapy in patients with CF positive for P. aeruginosa, aged 6 years and older with mild to moderate lung disease.

\section{Methods}

Study design and patients

This was an open-label, single arm study in CF patients with P. aeruginosa infection. The study consisted of screening period (5 to 26 days) to test the presence of P. aeruginosa (Visit 1), a baseline visit (Visit 2), a visit one week after baseline visit (Visit 3), followed by a visit after 28 days on-treatment period (Visit 4) and subsequently a visit after 28 days off-treatment period (Visit 5 , end of study). All patients were treated with tobramycin monotherapy, either as an inhalation solution (TIS) $300 \mathrm{mg}$ twice daily (BID) or as an inhalation powder (TIP) $128 \mathrm{mg} \mathrm{BID.} \mathrm{FEV} 1, \mathrm{LCl}$ and bacterial load in sputum (colony forming units [CFU]) were assessed at baseline, after 1, 4 and 8 weeks of treatment. Spirometric and LCl assessments were conducted before or at least one hour after the inhalation of the drug. MBW measurements to assess the LCl were performed with the ExhalyzerD (Eco Physics GmbH, Munich, Germany). The study design was approved by the independent ethics committee and institutional review boards; and was in accordance with the Declaration of Helsinki. 
The study enrolled patients diagnosed with CF aged 6 to 50 years, with a pulmonary infection of P. aeruginosa within the last 12 months and at screening. Patients with an elevated $\mathrm{LCl}$ of $\geq 7.5$ and $\mathrm{FEV}_{1}$ of $\geq 50 \%$ at screening, and those receiving inhaled tobramycin monotherapy in 28 days on/off regime in the past 3 month before screening were included. Informed consent was obtained from patients for having their data collected. Patients receiving more than one class of inhaled antipseudomonal antibiotic during the study or in the past 56 days prior to the baseline visit, or who used oral or intravenous antipseudomonal antibiotics within 28 days prior to the on-phase of the study drug or loop diuretics within 7 days prior to the first study medication administration, were excluded.

Study assessments

The primary endpoint was change in LCl after 4 weeks of treatment versus baseline. Secondary endpoints included change in $\mathrm{FEV}_{1}$ and $\mathrm{CFU}$ after week 4 following treatment; change of $\mathrm{LCl}$ after week 1 following treatment; change of $\mathrm{LCl}_{1} \mathrm{FEV}_{1}$ and $\mathrm{CFU}$ between week 4 (end of the study drug inhalation in the current treatment cycle) and week 8 (prior to the start of the study drug inhalation in the following treatment cycle); and correlation between the changes of $\mathrm{LCl} \mathrm{FEV}_{1}$ and CFU after weeks 1, 4 and 8 versus baseline, respectively.

For LCl assessment, the multiple breath washout device Exhalyzer D (Ecomedics, Zurich, Switzerland) was used, with Nitrogen as the tracer gas. All equipment and the device software were identical throughout the sites. LCI was determined according to the Exhalyzer D SOP of the manufacturer and all study sites have been provided with a device specific training before start of the study. For the measurements used to calculate the mean value, a quality control was done by a central assessor (MBW specialist).

Statistical analysis

Assuming a change of $5 \%$ in $\mathrm{FEV}_{1}$ with an intraindividual standard deviation of $9 \%$ between the on- and off-treatment cycles, 28 patients would provide $80 \%$ power on a 2-sided $5 \%$ significance level to detect this change. To compensate for protocol deviations and dropouts, 35 patients were planned to be recruited into this trial. All variables were summarized using descriptive statistics. Analyses were performed by using SAS Version 9.4.

Changes in LCl from baseline were analyzed using an analysis of variance (ANOVA) model. Estimates over time were presented as least squares (LS)-means, pairwise LS-mean differences along with $95 \%$ confidence intervals $(\mathrm{Cl})$ and 2-sided p-values for the pairwise differences between visits. If the baseline value was missing, then change was calculated from the data recorded at the screening. The primary analysis included patients with a valid observation at the baseline and post-baseline visits.

\section{Results}


In total, 17 patients (5 patients treated with TIS and 12 patients with TIP) were enrolled and completed the study. The majority of the patients ( 14 patients, $82.4 \%$ ) were aged $>17$ years, with an overall mean age of $26.4 \pm 9.99$ years and body mass index (BMI) of $21.1 \pm 2.46 \mathrm{~kg} / \mathrm{m}^{2}$. The study had a higher proportion of men (64.7\%) versus women (35.3\%). At baseline, mean LCl was $17.99 \pm 4.73(95 \% \mathrm{Cl}$ : 11.16-29.14) and $\mathrm{FEV}_{1}$ was $76.96 \pm 18.60 \%$ predicted (95\% Cl: $\left.44.66-115.5\right)$ (Fig. 1a). All patients demonstrated considerably elevated $\mathrm{LCl}$ of $>11$ (normal range 6.5-7.5) despite 3 patients having a normal lung function ( $\mathrm{FEV}_{1}>90 \%$ predicted) at baseline. The demographics and characteristics of patients at the baseline are presented in Table 1.

\begin{tabular}{|ll|}
\hline Age, years & $26.4(9.99)$ \\
\hline Men, $\mathrm{n}(\%)$ & $11(64.7)$ \\
\hline Height, cm & $171.12(12.8)$ \\
\hline Weight, kg & $62.6(12.9)$ \\
\hline Waist circumference, cm & $85.1(22.6)$ \\
\hline $\mathrm{BMI}, \mathrm{kg} / \mathrm{m}^{2}$ & $21.1(2.5)$ \\
\hline $\mathrm{LCl}$ & $17.99(4.7)$ \\
\hline $\mathrm{FEV}$ & $7 \% .96(18.6)$ \\
\hline
\end{tabular}

Data are expressed as mean (SD) unless indicated otherwise.

$\mathrm{BMI}$, body mass index; $\mathrm{FEV}_{1}$, forced expiratory volume in one second; $\mathrm{LCl}$, lung clearance index; $\mathrm{SD}$, standard deviation

Table 1. Patient demographics and baseline characteristics $(\mathrm{N}=17)$

The mean LCl decreased slightly over time from baseline. At week 4, LCl decreased by $0.88(17.10 \pm 0.84$; $95 \%$ Cl: $15.31-18.88)$ from baseline, which was statistically non-significant $(p=0.41)$. Overall, $8(47 \%)$ patients showed an improved $\mathrm{LCl}$ at week 4 from baseline. At least 3 patients showed worsening of $\mathrm{LCl}$ despite improvement in $\mathrm{FEV}_{1}$ (Table 2). 
Table 2

Lung function parameters after visit 4 versus baseline

\begin{tabular}{|c|c|c|c|c|c|}
\hline Patient \# & Age & $\mathrm{FEV}_{1}$ at baseline (\% predicted) & $\begin{array}{l}\mathrm{dLCl} \text { in } \\
\% \text { of baseline }\end{array}$ & $\begin{array}{l}\mathrm{dFEV}_{1} \text { in } \\
\% \text { of baseline }\end{array}$ & dCFU $[/ g]$ \\
\hline 1 & 17 & 82.6 & $29.8 \%$ & $11.0 \%$ & $-17,120$ \\
\hline 2 & 17 & 84.7 & $3.8 \%$ & $10.6 \%$ & - \\
\hline 3 & 37 & 71.5 & $-42.4 \%$ & $7.2 \%$ & $-224,700$ \\
\hline 4 & 19 & 68.2 & $-24.6 \%$ & $7.0 \%$ & - \\
\hline 5 & 19 & 115.5 & $-19.8 \%$ & $4.4 \%$ & - \\
\hline 6 & 24 & 109.9 & $10,5 \%$ & $2.7 \%$ & $-12,200$ \\
\hline 7 & 35 & 77.8 & $-3.0 \%$ & $2.1 \%$ & $-12,640$ \\
\hline 8 & 37 & 79,5 & $6.7 \%$ & $0.9 \%$ & -40 \\
\hline 9 & 22 & 44.7 & $-24.1 \%$ & $0.6 \%$ & 20,800 \\
\hline 10 & 18 & 65.9 & $-4.8 \%$ & $0.0 \%$ & $-225,600$ \\
\hline 11 & 41 & 61.9 & $-4.6 \%$ & $0.0 \%$ & $-8,800$ \\
\hline 12 & 30 & 51.5 & $-15.6 \%$ & $-1.0 \%$ & 100 \\
\hline 13 & 8 & 88.9 & $-6.9 \%$ & $-2.2 \%$ & 732 \\
\hline 14 & 43 & $101.1 \%$ & $8.7 \%$ & $-5.1 \%$ & 14,000 \\
\hline 15 & 34 & $67.9 \%$ & $17.1 \%$ & $-6.9 \%$ & $-10,040$ \\
\hline 16 & 23 & $75.3 \%$ & $4.8 \%$ & $-12.5 \%$ & 29,600 \\
\hline 17 & 24 & $68.6 \%$ & $36.2 \%$ & $-13.0 \%$ & - \\
\hline
\end{tabular}

The mean $\mathrm{FEV}_{1}$ increased by $0.52 \%(77.48 \pm 20.56 ; 95 \% \mathrm{Cl}$ : $66.91-88.05)$ at week 4 from baseline, which was not statistically significant $(p=0.70)$. At week 4,9 patients $(53 \%)$ showed an improved $F E V_{1}$ and $P$. aeruginosa reduced by $30481.3 \mathrm{CFU} / \mathrm{mL}$ (26113.0 CFU/mL; 95\% Cl: (-32035.02-84261.05) as compared to baseline (56594.3). However, the change in CFU was not statistically significant $(p=0.35)$. The mean LCl decreased slightly $(-0.479)$ after 1 week of drug inhalation $(p=0.59)$. The changes in $\operatorname{LCl}(p=0.42)$, $\mathrm{FEV}_{I}(\mathrm{p}=0.39)$, and CFU $(p=0.35)$ from week 4 to week 8 were statistically non-significant (Fig. 1b-d). A statistically significant positive correlation was observed between $\mathrm{LCl}$ and CFU at week $1(r=0.59, p=$ 
$0.0321)$ and week $4(r=0.79, p=0.0046)$ from baseline. A negative correlation $(r=-0.64)$ was seen between $\mathrm{FEV}_{1}$ and CFU at week 4 from baseline, which was statistically significant $(p=0.0462)$.

Overall, 6 adverse events (AEs) occurred in 5/17 patients (29.4\%) (3 patients on TIP and 2 patients on TIS), most of which were related to respiratory, thoracic and mediastinal disorders $(n=3,17.6 \%)$. Most of these were mild or moderate in severity (Table 3 ).

Table 3

Adverse event

\begin{tabular}{|c|c|c|c|}
\hline System organ class & $\begin{array}{l}\text { TIS (N = 5) } \\
n(\%)\end{array}$ & $\begin{array}{l}\operatorname{TIP}(\mathrm{N}=12) \\
\mathrm{n}(\%)\end{array}$ & $\begin{array}{l}\text { Overall }(\mathrm{N}=17) \\
\mathrm{n}(\%)\end{array}$ \\
\hline Any MedDRA system organ class & $2(40.0)$ & $3(25.0)$ & $5(29.4)$ \\
\hline Injury, poisoning and procedural complications & $1(20.0)$ & $0(0.0)$ & $1(5.9)$ \\
\hline Sunburn & $1(20.0)$ & $0(0.0)$ & $1(5.9)$ \\
\hline Investigations & $1(8.3)$ & $0(0.0)$ & $1(5.9)$ \\
\hline Forced expiratory volume decreased & $1(8.3)$ & $0(0.0)$ & $1(5.9)$ \\
\hline Respiratory, thoracic and mediastinal disorders & $2(16.7)$ & $1(20.0)$ & $3(17.6)$ \\
\hline Cough & $1(8.3)$ & $0(0.0)$ & $1(5.9)$ \\
\hline Haemoptysis & $0(0.0)$ & $1(20.0)$ & $1(5.9)$ \\
\hline Obstructive airways disorder & $1(8.3)$ & $0(0.0)$ & $1(5.9)$ \\
\hline \multicolumn{4}{|c|}{$\begin{array}{l}\text { TIS, Tobramycin inhalation solution; TIP, Tobramycin inhalation powder. Percentages are based on } N \\
\text { of each group in safety set. A patient with multiple occurrences of an AE is counted only once in the } \\
\text { AE category. A patient with multiple adverse events within a primary system organ class is counted } \\
\text { only once in each system organ class total row. MedDRA version } 20.0 \text { has been used for coding of } \\
\text { adverse events. }\end{array}$} \\
\hline
\end{tabular}

\section{Discussion}

It has been shown that lung damage induced by inflammation precedes $\mathrm{FEV}_{1}$ decline [10]. LCI derived from MBW not only reflects ventilation defects in the respiratory tract, but also helps identify early dysfunction in small airways that are not easily identified with traditional spirometry methods [13]. Therefore, the present study assessed the clinical utility of $\mathrm{LCl}$ for assessing the response to inhaled tobramycin antibiotic therapy in patients with CF positive for P. aeruginosa. In the present study, three patients had a significantly elevated $\mathrm{LCl}$ despite having a normal $\mathrm{FEV}_{1} \%$ at baseline. In addition, the single normalized differences in $\mathrm{LCl}$ at week 4 versus baseline for individual patients were higher than the respective normalized $\mathrm{FEV}_{1}$ differences (Table 2 and Fig. 2), indicating a higher sensitivity of lung function assessment with MBW compared to classical spirometry. Similar findings from previously 
published data also showed that $\mathrm{LCl}$ provides a more sensitive overall estimate of ventilation inhomogeneity compared to $\mathrm{FEV}_{1}$, at least in patients with mild lung disease [16].

There is increasing evidence on the clinical utility of $\mathrm{LCl}$. In addition to $\mathrm{LCl}$ being used as a clinical endpoint $[5,15]$, it has also been used to assess mucociliary clearance in young children [17] treated with CFTR-modulators [15] and to monitor disease progression [18], or both [19]. However, this study with inhaled tobramycin demonstrated that changes in $\mathrm{LCl}, \mathrm{FEV}_{1}$ and $\mathrm{CFU}$ at week 1, 4 and 8 were not statistically significant. There was no specific trend observed with respect to correlation between the changes of $\mathrm{LCl}, \mathrm{FEV}_{1}$ and CFU after week 1,4 and 8 versus baseline. This may be attributed to the heterogeneity in $\mathrm{LCl}$ response to antibiotic treatment seen in the individual data for MBW and spirometry shown in Fig. 2. These results are in line with previously published studies [20,21] and pooled analyses [22]. Despite the use of a more efficient therapy (inhaled formulation) in terms of an increased bioavailability of tobramycin in sputum we observed heterogeneity in the present study which is comparable to the findings seen with intravenous antibiotic treatment in children with CF [20]. In contrast to the outcome from the present study, a short-term study (one month) with $32 \mathrm{CF}$ children on intravenous antibiotic treatment showed a significant improvement in $\mathrm{LCl}$ compared with $\mathrm{FEV}_{1}$ [23]. However, data about $\mathrm{LCl}$ as outcome measure for short-term efficacy of antibiotics in CF remains very limited.

The observed heterogeneity in lung function response to therapy can partly be attributed to the nonresponders, which could be due to a few patients becoming refractory to inhaled antibiotics [24]. Further, there were single cases of negative, or positive change in CFU in some patients however, such findings are not conclusive, also because not all patients were able to expectorate sputum and thus, CFU data was missing for some patients. In addition, CFU assessment in general is characterized by huge intraindividual variation and therefore, any non-significant findings have to be evaluated with caution. Based on this data, one may speculate that therapy response in these patients with mild to moderate lung disease, chronically treated with inhaled tobramycin was weak and/or heterogeneous. At least 3 patients showed worsening of $\mathrm{LCl}$ despite an improvement in $\mathrm{FEV}_{1}$, which could be due to increased ventilation inhomogeneity in newly ventilated lung regions following inhaled antibiotic therapy (eg. by reduced airtrapping) [21, 25].

In addition, chest physiotherapy to remove sticky mucus from the airways, prior to lung function testing may also lead to heterogeneity in $\mathrm{LCl}$ response. The inherent ventilation inhomogeneity combined with the clearance of mucus plugged airways (after chest physiotherapy) which were previously poorly ventilated (at baseline) leads to an increased LCI [26]. Indeed, a mean reduction of 0.2 in LCl response 30 min after physiotherapy was observed in CF patients with lung disease of varying severity, suggesting unpredictability of short-term physiotherapy on LCl responses [27]. Similar to previously reported studies, the standard physiotherapy performed in the present study is strongly dependent on the therapist's discretion as well as on the daily performance and adherence of the individual CF patient. Although chest physiotherapy is typically performed before inhalation and is done at least $1 \mathrm{~h}$ prior to MBW, there is no guidance on the timing for the physiotherapy at each visit. Hence, chest physiotherapy could have 
affected the outcome of lung function testing in this study to a certain degree. A detailed documentation of the timing and type of physiotherapy relative to MBW lung function testing in future clinical trials using $\mathrm{LCl}$ as a study endpoint is therefore recommended [26].

Based on the results from the present study as well as from available literature, it can be hypothesized that $\mathrm{LCl}$ can be an appropriate endpoint for efficacy trials in CF patients if the heterogeneity in lung function is limited by enrolling only drug naïve patients. Furthermore, including younger patients with milder lung disease and specifically defined time points for chest physiotherapy; while excluding false negative changes in lung function outcomes resulting from physiotherapy is recommended.

Overall, treatment with tobramycin showed a favorable safety profile. During the study period six AEs were reported, all of which were mild and moderate in severity, which is in line with previously published phase III data $[28,29]$.

A major limitation of the present study is the small sample size because of difficulties with patient enrollment and recruitment. The standard of care changed during the setup of the study, i.e., the majority of $P$. aeruginosa positive CF patients were to be treated with continuous inhaled sequential antibiotic combinations [30]. Hence, enrollment of patients on monotherapy was a challenge and thus, the study could include only 17 patients versus 35 patients that were planned to be enrolled.

\section{Conclusions}

In summary, the changes in $\mathrm{LCl}, \mathrm{FEV}_{1}$ and CFU were statistically non-significant at week 1,4 and 8 when compared with baseline which may be due to the heterogeneity in $\mathrm{LCl}$ response to antibiotic treatment and the low evaluable sample size.

Even if $\mathrm{LCl}$ is not identified as the ideal clinical efficacy endpoint for studies with antibiotic treatment (either intravenous or inhaled), it does not jeopardize the overall value of $\mathrm{LCl}$ as a more sensitive lung function parameter for CF patients with mild to moderate lung disease. Considering previously published data, $\mathrm{LCl}$ seems to be a suitable endpoint for drugs affecting the mucociliary clearance and to assess disease progression in cystic fibrosis. However, $\mathrm{LCl}$ alone does not seem to be the ideal clinical endpoint for efficacy studies with antibiotic treatment (either intravenous or inhaled) in small groups of CF patients.

\section{Abbreviations}




\begin{tabular}{ll} 
AE & Adverse events \\
\hline ANOVA & Analysis of variance \\
\hline BID & Twice daily \\
\hline BMI & Body mass index \\
\hline CF & Cystic fibrosis \\
\hline CFTR & Cystic fibrosis transmembrane conductance regulator \\
\hline CFU & Colony forming units \\
\hline Cl & Confidence intervals \\
\hline d & Difference \\
\hline FEV1 & Forced expiratory volume in one second \\
\hline IVA & Ivacaftor \\
\hline LCl & Lung clearance index \\
\hline LS & Least squares \\
\hline LUM & Lumacaftor \\
\hline MBW & Multiple breath washout \\
\hline P. aeruginosa & Pseudomonas aeruginosa \\
\hline ppFEV1 & Percent predicted FEV \\
\hline SD & Standard deviation \\
\hline TIP & Tobramycin inhalation powder \\
\hline TIS & Tobramycin inhalation solution \\
\hline
\end{tabular}

\section{Declarations}

Ethics approval and consent to participate: The study design was approved by the independent ethics committee and institutional review boards (Supplementary material); and was in accordance with the Declaration of Helsinki. Informed consent was obtained from each patient (or from parents for children $<16$ years of age) in writing before randomization.

Consent for publication: Not applicable.

Competing interests: SS has served as an investigator in clinical trials for Galapagos, Proteostasis, Celtaxsys, Flatley, Novartis Pharma GmbH and Vertex Pharmaceuticals Incorporated and has consulted 
for Teva $\mathrm{GmbH}$, Novartis Pharma $\mathrm{GmbH}$, Chiesi GmbH and Vertex Pharmaceuticals Incorporated. SN and UM have nothing to disclose. CS and JZ are employees of Novartis Pharma GmbH.

Funding: The funding for study design, data collection, analysis, and interpretation was provided by Novartis Pharma GmbH. Medical writing support for the manuscript, in accordance with Good Publication Practice (GPP3) guidelines (http://www.ismpp.org/gpp3) was funded by Novartis Healthcare Pvt. Ltd, Hyderabad, India.

Author contributions: All authors assume responsibility for the accuracy of the data interpretation and approved the manuscript for publication. UM, CS, and JZ contributed to study conception, protocol development, data analysis and interpretation of data. SN and UM contributed on the interpretation of data and critical review of the study, SS and JZ drafted the first version of the manuscript. All authors helped with the review and finalization of the manuscript.

Acknowledgements: The authors thank Nihal Maremanda and Lakshmi Deepa (Novartis Healthcare Private Ltd, Hyderabad, India) for medical writing support and Mirjam Stahl, Division of Pediatric Pulmonology and Allergy and Cystic Fibrosis Center, Department of Pediatrics, University of Heidelberg, Germany, for discussion of the LCl data

Availability of data and materials: The data generated during and/or analyzed during the current study are available from the corresponding author upon reasonable request.

\section{References}

1. Riordan JR, Rommens JM, Kerem B, Alon N, et al. Identification of the cystic fibrosis gene: cloning and characterization of complementary DNA. Science. 1989;245:1066-73.

2. Elborn JS. Cystic fibrosis. Lancet. 2016;388:2519-31.

3. Langton Hewer SC and Smyth AR. Antibiotic strategies for eradicating Pseudomonas aeruginosa in people with cystic fibrosis. Cochrane Database Syst Rev. 2017:4:CD004197.

4. Smith S, Rowbotham NJ, Regan KH. Inhaled anti-pseudomonal antibiotics for long-term therapy in cystic fibrosis. Cochrane Database Syst Rev. 2018;3:CD001021.

5. Stanojevic S, Ratjen F. Physiologic endpoints for clinical studies for cystic fibrosis. J Cyst Fibros. 2016;15:416-23.

6. Pittman JE, Davis SD. Decline in Forced Expiratory Volume in 1 Second in Cystic Fibrosis-Watch the Pendulum Swing. J Pediatr. 2016;169:7-9.

7. Konstan MW, McKone EF, Moss RB, Marigowda G, et al. Assessment of safety and efficacy of longterm treatment with combination lumacaftor and ivacaftor therapy in patients with cystic fibrosis homozygous for the F508del-CFTR mutation (PROGRESS): a phase 3, extension study. Lancet Respir Med. 2017;5:107-18. 
8. Sawicki GS, McKone EF, Pasta DJ, Millar SJ, et al. Sustained benefit from ivacaftor demonstrated by combining clinical trial and cystic fibrosis patient registry data. American journal of respiratory and critical care medicine. 2015;192:836-42.

9. Mott LS, Park J, Murray CP, Gangell CL, et al. Progression of early structural lung disease in young children with cystic fibrosis assessed using CT. Thorax 2012;67:509-16.

10. Breuer O, Caudri D, Stick S, Turkovic L. Predicting disease progression in cystic fibrosis. Expert Rev Respir Med. 2018;12:905-17.

11. Judge EP, Dodd JD, Masterson JB, Gallagher CG. Pulmonary abnormalities on high-resolution CT demonstrate more rapid decline than FEV1 in adults with cystic fibrosis. Chest. 2006;130:1424-32.

12. Subbarao P, Milla C, Aurora P, Davies JC, et al. Multiple-Breath Washout as a Lung Function Test in Cystic Fibrosis. A Cystic Fibrosis Foundation Workshop Report. Ann Am Thorac Soc. 2015;12:932-9.

13. Kent $L$, Reix $P$, Innes JA, Zielen $S$, et al. Lung clearance index: evidence for use in clinical trials in cystic fibrosis. J Cyst Fibros. 2014;13:123-38.

14. Horsley AR, Gustafsson PM, Macleod KA, Saunders C, et al. Lung clearance index is a sensitive, repeatable and practical measure of airways disease in adults with cystic fibrosis. Thorax. 2008;63:135-40.

15. Ratjen F, Hug C, Marigowda G, Tian S, et al, 2017. Efficacy and safety of lumacaftor and ivacaftor in patients aged 6-11 years with cystic fibrosis homozygous for F508del-CFTR: a randomised, placebocontrolled phase 3 trial. Lancet Respir Med. 2017;5:557-567. Epub 2017 Jun 9.

16. Davies JC, Sheridan H, Lee P-S, Song T, et al. Effect of ivacaftor on lung function in subjects with CF who have the G551DCFTR mutation and mild lung disease: a comparison of lung clearance index (LCI) vs. spirometry. J Cyst Fibros. 2012;11(Suppl. 1):S15.

17. Davies J, Sheridan H, Bell N, Cunningham S, et al., Assessment of clinical response to ivacaftor with lung clearance index in cystic fibrosis patients with a G551DCFTR mutation and preserved spirometry: a randomised controlled trial. Lancet Respir. Med. 2013;1:630-8.

18. Svedberg M, Gustafsson PM, Robinson PD, Rosberg M, et al. Variability of lung clearance index in clinically stable cystic fibrosis lung disease in school age children. J Cyst Fibros. 2018;17:236-41.

19. Ellemunter $\mathrm{H}$, Eder J, Fuchs S, Gappa M, et al. Long-term improvement of lung clearance index in patients with mild cystic fibrosis lung disease: Does hypertonic saline play a role? J Cyst Fibros. 2016 Jan;15(1):123-6.

20. Welsh L, Nesci C, Tran H, Tomai M, et al. Lung clearance index during hospital admission in schoolage children with cystic fibrosis. J Cyst Fibros. 2014;13:687-91.

21. Yammine S, Bigler A, Casaulta C, Singer F, et al. Reasons for heterogeneous change in LCl in children with cystic fibrosis after antibiotic treatment. Thorax. 2014;69:183.

22. Sonneveld N, Stanojevic S, Amin R, Aurora P, et al. Lung clearance index in cystic fibrosis subjects treated for pulmonary exacerbations. Eur Respir J. 2015;46:1055-64. 
23. Hatziagorou E, Avramidou V, Kirvassilis F, Tsanakas J. Use of lung clearance index to assess the response to intravenous treatment in cystic fibrosis. Hippokratia. 2015;19:47-52.

24. VanDevanter DR, Ballmann M, Flume PA. Applying clinical outcome variables to appropriate aerosolized antibiotics for the treatment of patients with cystic fibrosis. Respiratory Medicine. 2011;105: S18-S23.

25. Robinson PD, Goldman MD, Gustafsson PM. Inert gas washout: theoretical background and clinical utility in respiratory disease. Respiration. 2009;78:339-55.

26. Grosse-Onnebrink J, Mellies U, Olivier M, Werner C, et al. Chest physiotherapy can affect the lung clearance index in cystic fibrosis patients. Pediatr Pulmonol. 2017;52:625-31.

27. Pfleger A, Steinbacher M, Schwantzer G, Weinhandl E, et al. Short-term effects of physiotherapy on ventilation inhomogeneity in cystic fibrosis patients with a wide range of lung disease severity. $J$ Cyst Fibros. 2015;14:627-31.

28. Ramsey BW, Pepe MS, Quan JM, Otto KL, et al. Intermittent administration of inhaled tobramycin in patients with cystic fibrosis. Cystic Fibrosis Inhaled Tobramycin Study Group. N Engl J Med. 1999;340:23-30.

29. Konstan MW, Flume PA, Kappler M, Chiron R, et al. Safety, efficacy and convenience of tobramycin inhalation powder in cystic fibrosis patients: The EAGER trial. J Cyst Fibros. 2011;10:54-61.

30. Dasenbrook EC, Konstan MW, VanDevanter DR. Association between the introduction of a new cystic fibrosis inhaled antibiotic class and change in prevalence of patients receiving multiple inhaled antibiotic classes. J Cyst Fibros. 2015;14:370-5.

\section{Figures}


Figure 1: Lung function parameters (LCI and FEV $)$ and $C F U$ at baseline and over time

a

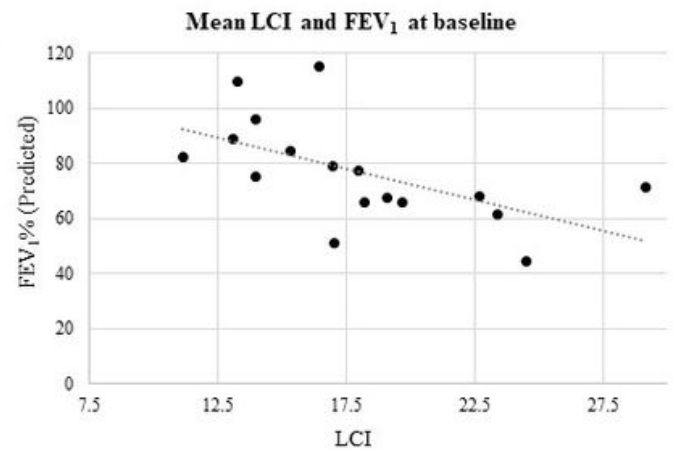

c

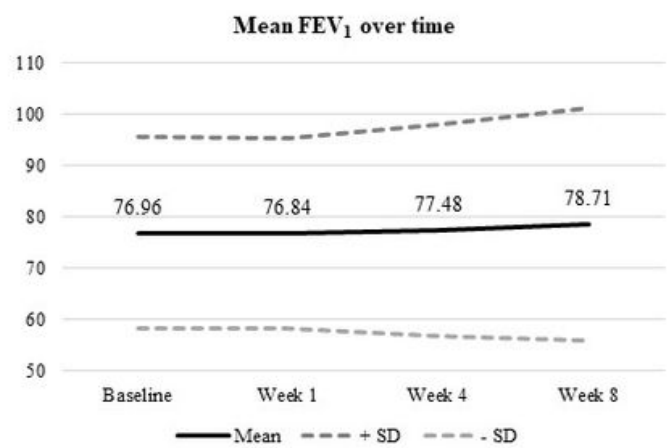

b

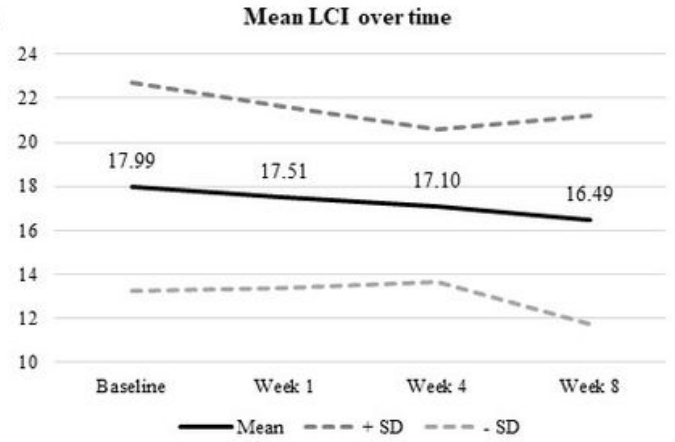

d

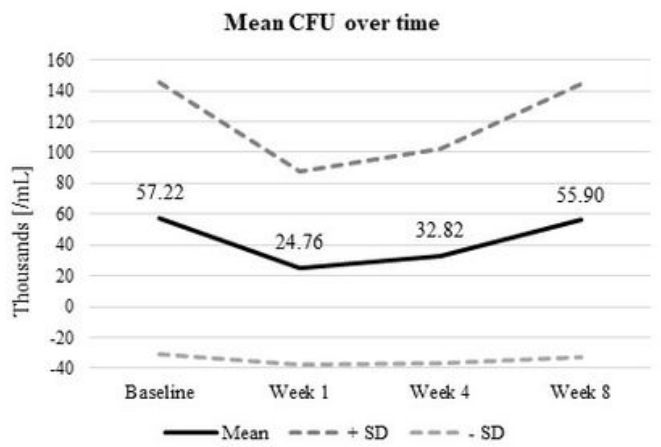

\section{Figure 1}

Lung function parameters (LCl and FEV1) and CFU at baseline and over time. CFU, colony forming units; FEV1, forced expiratory volume in one second; LCl, lung clearance index; SD, standard deviation

Figure 2: Matched pairs of relative changes in LCI and FEV $\mathrm{F}_{1}$ at week 4 from baseline

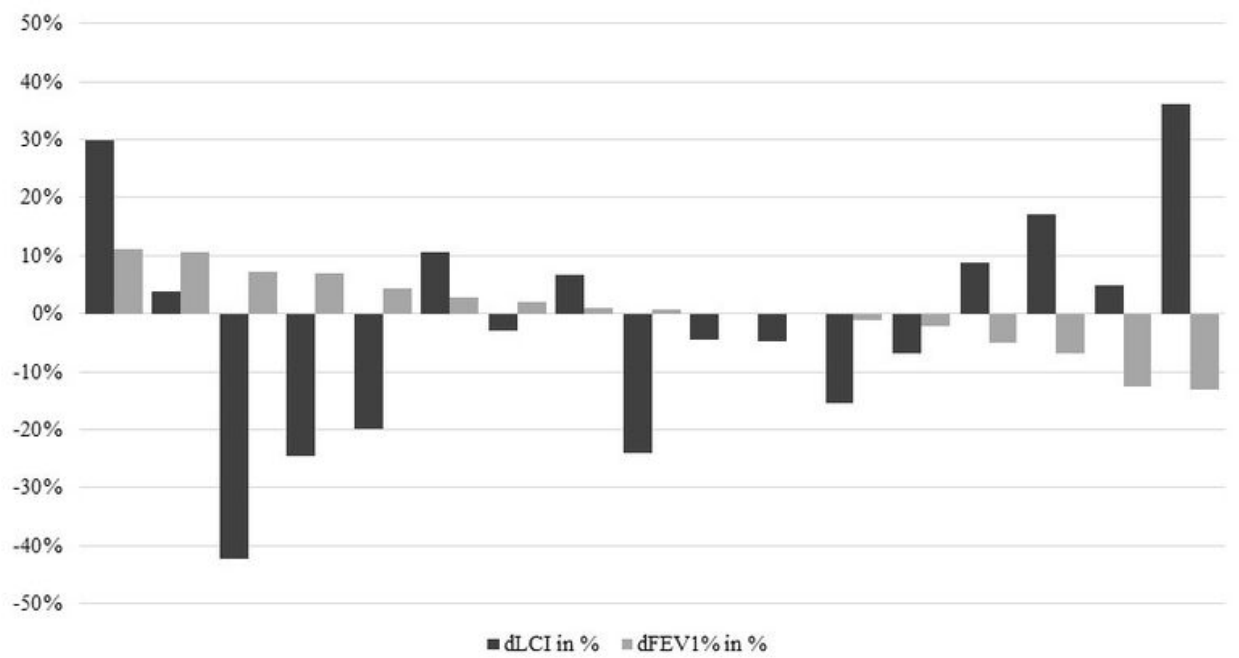


Figure 2

Matched pairs of relative changes in LCl and FEV1 at week 4 from baseline. $d$, difference; FEV1, forced expiratory volume in one second; $\mathrm{LCl}$, lung clearance index

\section{Supplementary Files}

This is a list of supplementary files associated with this preprint. Click to download.

- Supplementarymaterial.docx 